\title{
An In Vitro Microfluidic Alveolus Model to Study Lung Biomechanics
}

\author{
Vardhman Kumar ${ }^{1}$, Sajeesh Kumar Madhurakkat Perikamana ${ }^{2}$, Aleksandra Tata ${ }^{3}$, \\ Jiaul Hoque ${ }^{2}$, Anna Gilpin ${ }^{1}$, Purushothama Rao Tata ${ }^{3,4}$ and Shyni Varghese ${ }^{1,2,5 *}$ \\ ${ }^{1}$ Department of Biomedical Engineering, Duke University, Durham, NC, United States, ${ }^{2}$ Department of Orthopaedic Surgery, \\ Duke University School of Medicine, Durham, NC, United States, ${ }^{3}$ Department of Cell Biology, Duke University School of \\ Medicine, Durham, NC, United States, ${ }^{4}$ Regeneration Next, Duke University, Durham, NC, United States, ${ }^{5}$ Department of \\ Mechanical Engineering and Material Science, Duke University, Durham, NC, United States
}

\section{OPEN ACCESS}

Edited by:

Loredana De Bartolo,

National Research Council (CNR), Italy

Reviewed by:

Josue Sznitman,

Technion Israel Institute of

Technology, Israel

Ludovica Cacopardo,

University of Pisa, Italy

${ }^{*}$ Correspondence:

Shyni Varghese

shyni.varghese@duke.edu

Specialty section:

This article was submitted to

Tissue Engineering and Regenerative

Medicine,

a section of the journal

Frontiers in Bioengineering and

Biotechnology

Received: 05 January 2022

Accepted: 25 January 2022

Published: 18 February 2022

Citation:

Kumar $V$,

Madhurakkat Perikamana SK, Tata A,

Hoque J, Gilpin A, Tata PR and

Varghese $S$ (2022) An In Vitro

Microfluidic Alveolus Model to Study

Lung Biomechanics.

Front. Bioeng. Biotechnol. 10:848699.

doi: 10.3389/fbioe.2022.848699
The gas exchange units of the lung, the alveoli, are mechanically active and undergo cyclic deformation during breathing. The epithelial cells that line the alveoli contribute to lung function by reducing surface tension via surfactant secretion, which is highly influenced by the breathing-associated mechanical cues. These spatially heterogeneous mechanical cues have been linked to several physiological and pathophysiological states. Here, we describe the development of a microfluidically assisted lung cell culture model that incorporates heterogeneous cyclic stretching to mimic alveolar respiratory motions. Employing this device, we have examined the effects of respiratory biomechanics (associated with breathing-like movements) and strain heterogeneity on alveolar epithelial cell functions. Furthermore, we have assessed the potential application of this platform to model altered matrix compliance associated with lung pathogenesis and ventilator-induced lung injury. Lung microphysiological platforms incorporating human cells and dynamic biomechanics could serve as an important tool to delineate the role of alveolar micromechanics in physiological and pathological outcomes in the lung.

Keywords: microfluidics, organ-on-a-chip, lung, microphysiological system, in vitro system

\section{INTRODUCTION}

The lung is a key organ that ensures blood oxygenation by means of respiration. Mechanical cues arising from cyclic expansion and contraction of alveoli during breathing have an important role in maintaining tissue homeostasis (Ingenito et al., 2005; Faffe and Zin, 2009; Perlman et al., 2011; Chen et al., 2014; Hsia et al., 2016; Knudsen and Ochs, 2018; Plantier et al., 2018). Conventional in vitro models of lung tissues frequently neglect the dynamic tissue biomechanics associated with respiration. Development of microfluidic organon-a-chip technology enables recapitulation of mechanical and structural aspects of the organ microenvironment, thus potentially narrowing the gap between in vitro and in vivo models (Bhatia and Ingber, 2014; Aung et al., 2016, 2020; Agrawal et al., 2017; Kumar and Varghese, 2019; Low et al., 2021). Toward this, various microphysiological platforms such as lung-on-achip, airway-on-a-chip, and alveolus-on-chip have been developed to model lung functions such as barrier properties, immune responses to infections, and lung pathologies such as asthma, edema, thrombosis, and lung cancer progression (Huh et al., 2010, 2012; Stucki et al., 2015, 2018; Benam et al., 2016a, 2016b, 2017; Jain et al., 2018; Park et al., 2018; Felder et al., 2019; Elias-Kirma et al., 2020; Ishahak et al., 2020; Jimenez-Valdes et al., 2020; Khalid et al., 
2020; Mejías et al., 2020; Nawroth et al., 2020; Shrestha et al., 2020, 2021; Zamprogno et al., 2021).

Lung distention occurs in three dimensions (3D) as a result of not only the alveolar air pressure but also the difference between the alveolar air pressure and the pleural fluid pressure, the transpulmonary pressure. Model systems incorporate such dynamic mechanical movements associated with breathing using deformable membranes subjected to dynamic pressure (Guenat and Berthiaume, 2018). While most in vitro studies and microphysiological systems incorporating dynamic stretch have been limited to generating in-plane strain or uniaxial strain in the $5-12 \%$ range reported in vivo (Birukov et al., 2003; Guenat and Berthiaume, 2018; Nossa et al., 2021; Sznitman, 2021), recent studies have delved into incorporating out-of-plane stretching to mimic the $3 \mathrm{D}$ movements of the alveoli during respiration (Stucki et al., 2018; Doryab et al., 2021a; Huang et al., 2021; Zamprogno et al., 2021). These advances offer unique in vitro tools to study the micromechanical changes such as the strain heterogeneity that develops as a result of the out-of-plane stretch and its subsequent role in lung physiology and pathology. Although the precise strain profile that develops in the lung during respiration is yet to be accurately mapped, it is well established that not just different regions of the lung but even a single alveolus experiences varying strains during respiration (Roan and Waters, 2011). These spatially varying mechanical cues have been shown to be associated with several lung conditions and vulnerabilities. For example, regions with intrinsically high strains-such as in aerated alveoli next to fluid-filled alveoli-are prone to experiencing increased strains during mechanical ventilation, thus predisposing them to ventilator-induced lung injury (VILI) (Perlman et al., 2011; Smith, 2016). Apart from such spatial variations in strain during breathing, progressive changes in local tissue mechanics (e.g., changes in compliance) are key characteristics of various respiratory disorders such as pulmonary fibrosis and emphysema (Ingenito et al., 2005; Faffe and Zin, 2009; Plantier et al., 2018; Hurtado et al., 2020).

In this study, we report a microfluidic alveolar tissue model that mimics dynamic out-of-plane stretching akin to alveolar inflation and deflation associated with breathing. The device consists of a fluidic and pneumatic layer separated by a thin polydimethylsiloxane (PDMS) membrane, which was functionalized by covalent conjugation of collagen-I to enable cell culture. We characterized the heterogeneous strain experienced by the membrane as a result of breathing-like movements by using computational analyses and examined the effect of spatial heterogeneity on cell alignment. Employing this platform, we also examined the effect of biomechanics on the function of alveolar epithelial cells. Specifically, we studied the effect of breathing-like movements on surfactant production by alveolar epithelial cells and how it is affected by heterogeneous strain and altered matrix compliance. Furthermore, we incorporated transpulmonary pressure into the device to have the membrane deform in response to a combination of pneumatic and hydrostatic pressure. Using this approach, we determined the applicability of this platform to model ventilator-induced lung injury (VILI). Finally, we also examined the potential of the platform to support the culture of human primary alveolar epithelial type 2 (AT2) cells and AT2 cells derived from human induced pluripotent stem cells (hiPSC).

\section{METHODS}

\section{Photolithography of the Master Mold}

Silicon wafers (UniversityWafers) were used for patterning arrays of $200-\mu \mathrm{m}$-wide and $100-\mu \mathrm{m}$-high channels by using SU-8 photolithography. Briefly, $4 \mathrm{ml}$ of SU-8 100 photoresist was spin-coated on a cleaned wafer at $3,000 \mathrm{rpm} / \mathrm{s}$ for $30 \mathrm{~s}$. The wafer was baked at $65^{\circ} \mathrm{C}$ for $10 \mathrm{~min}$, followed by $95^{\circ} \mathrm{C}$ for $30 \mathrm{~min}$. The wafer was then exposed to $365 \mathrm{~nm}$ wavelength light through a custom photomask designed in AutoCAD and baked at $65^{\circ} \mathrm{C}$ for $1 \mathrm{~min}$ and $95^{\circ} \mathrm{C}$ for $10 \mathrm{~min}$. The wafer was then rinsed with $\mathrm{SU}-8$ developer to remove the undeveloped photoresist. The resulting master mold was cleaned with isopropanol followed by water and stored until use.

\section{Device Fabrication, Assembly, and Operation}

To fabricate the device, a 10:1 (base:crosslinker) polydimethylsiloxane (PDMS) (Sylgard 184, Dow Inc.) precursor solution containing the crosslinker was poured onto the master mold and allowed to cure for $2 \mathrm{~h}$ at $60^{\circ} \mathrm{C}$. Post curing, PDMS was cut around the channels and $8 \mathrm{~mm}$ diameter holes were punched in the top fluidic layer and bottom pneumatic layer to create cell culture chambers and pneumatic chambers, respectively (Figure 1A). The same channel dimensions were used for both fluidic and pneumatic channels. One-mm-diameter inlet and outlet were punched in the fluidic layer, and a 1-mmdiameter inlet was punched in the pneumatic layer of the device (Figure 1A). PDMS membranes were prepared by curing the precursor solution between two glass slides separated using stainless steel spacers with a thickness of $250 \mu \mathrm{m}$. The cell culture chamber was capped on the top by a glass coverslip using either double-sided tape (for reversible adhesion) or plasma bonding (for irreversible adhesion). The fluidic microchannels were capped at the base by plasma bonding the PDMS membrane to the fluidic layer. Separately, the pneumatic chamber and the pneumatic channels were capped at the bottom by plasma bonding a rectangular coverslip to the pneumatic layer (Figure 1B). The fluidic and pneumatic layers were assembled using double-sided tape to get a reversible adhesion between the two layers. This enabled easy disassembly of the device for imaging. The PTFE tubing from the programmable air pump (Elveflow) was connected to the inlet of the pneumatic layer, while the inlets of the fluidic layer were fed through syringes loaded onto a syringe pump (Harvard Apparatus) at a rate of $50 \mu \mathrm{l} / \mathrm{h}$ unless stated otherwise. For all experiments involving breathing-like motions, sinusoidal pressure waveforms with a minimum and maximum at 0 and 50 mbar, respectively, at a frequency of $0.5 \mathrm{~Hz}$ were used unless stated otherwise. 


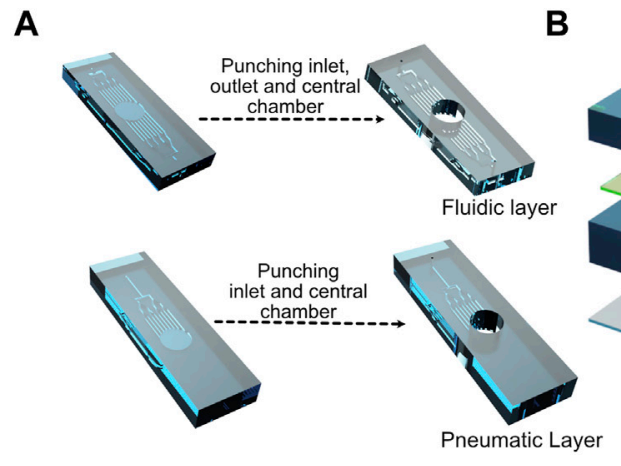

C

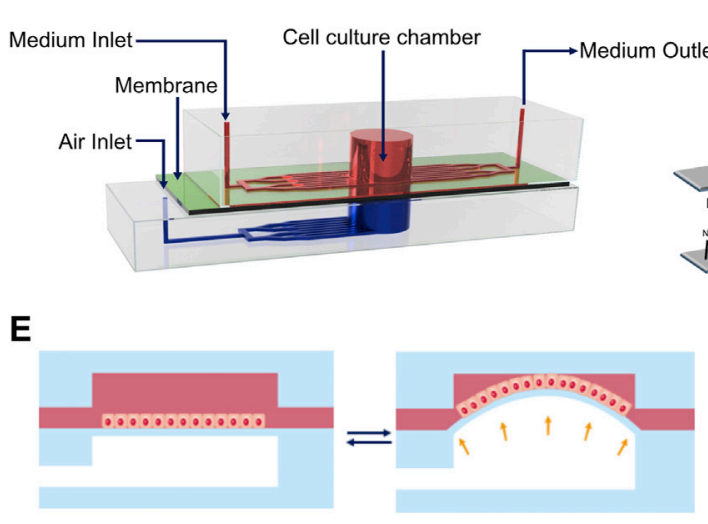

D

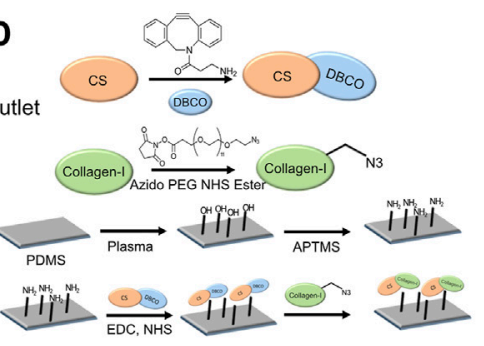

$\mathbf{F}$

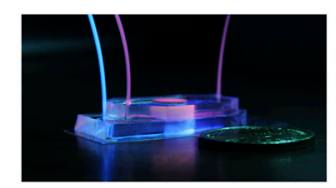

FIGURE 1 | (A) Computer-aided design (CAD) of the fabrication process of fluidic and pneumatic layers with microchannels. (B) Schematic of device assembly showing the different layers of the device in an exploded view. (C) Schematic depicting the assembled device. (D) Reaction scheme used for collagen functionalization of the PDMS membrane. (E) Schematic of breathing-like movements within the device. (F) Digital photograph of the device showing the media/cell chamber (red) and air chamber (blue).

\section{Computational Modeling to Determine Strain Fields}

The breathing movements of the membrane were modeled in COMSOL. The membrane was modeled as a cylindrical disc made from PDMS. A Mooney-Rivlin hyperelastic model (Rivlin, 1948) was used to describe the membrane:

$$
W_{s}=\sum_{i, j=0}^{n} C_{i, j}\left(I_{1}-3\right)^{i}\left(I_{2}-3\right)^{j}+\frac{1}{2} K\left(J_{e l}-1\right)^{2},
$$

where $I_{1}$ and $I_{2}$ are the first and second invariant of the left isochoric Cauchy-Green deformation tensor, $K$ is the bulk modulus, $J_{e l}$ is the elastic Jacobian, and $C_{i, j}$ are material parameters.

Two-parameter Mooney-Rivlin material parameters for the PDMS membrane of 10:1 base to crosslinker were approximated from Yoon et al. (2010). The values used are listed in Supplementary Table S1. Zero displacement boundary condition was applied at the curved surface of the cylindrical membrane, while load (resulting from air pressure) was applied at the base of the membrane. Displacement field was used to calculate the resulting radial and circumferential strain as a function of radial distance from the center of the membrane (Winkler et al., 2014).

$$
\begin{aligned}
& \text { Radial Strain }= \\
& \frac{\left|\left(x_{2}^{s}-x_{1}^{s}\right)+\left(y_{2}^{s}-y_{1}^{s}\right)+\left(z_{2}^{s}-z_{1}^{s}\right)\right|-\left|\left(x_{2}-x_{1}\right)+\left(y_{2}-y_{1}\right)+\left(z_{2}-z_{1}\right)\right|}{\left|\left(x_{2}-x_{1}\right)+\left(y_{2}-y_{1}\right)+\left(z_{2}-z_{1}\right)\right|}
\end{aligned}
$$

$$
\text { Circumferential Strain }=\frac{2 \pi r^{s}-2 \pi r}{2 \pi r},
$$

where $\left(x_{1}, y_{1}, z_{1}\right)$ and $\left(x_{2}, y_{2}, z_{2}\right)$ are coordinates of two arbitrary points on the membrane before stretching and $\left(x_{1}^{s}, y_{1}^{s}, z_{1}^{s}\right)$ and $\left(x_{2}^{s}, y_{2}^{s}, z_{2}^{s}\right)$ are the coordinates of the points after stretching. Similarly, $r$ and $r^{s}$ are the radial distance of a point from the center of the membrane before and after stretching, respectively.

\section{Synthesis of Chondroitin Sulfate-Dibenzocyclooctyne and Collagen Azide}

Five hundred milligrams of chondroitin sulfate (CS) (Alfa Aesar, J60341) was dissolved into $60 \mathrm{ml} \mathrm{DI}$ water. To this, $35 \mathrm{ml}$ of dimethyl 
sulfoxide (DMSO) was added, followed by $287.5 \mathrm{mg}$ of 1-ethyl-3-(3dimethylaminopropyl) carbodiimide hydrochloride (EDC.HCl) (TCI Chemical, D1601). Then $172.6 \mathrm{mg}$ of $N$-hydroxy succinimide (NHS) (Sigma, 130672) and $138.15 \mathrm{mg}$ of dibenzocyclooctyne-amine (DBCO-amine) (Click Chemistry Tools, A103) were dissolved in $5 \mathrm{ml}$ of DMSO and were added to the reaction mixture at $15-\mathrm{min}$ intervals. The reaction was continued for $24 \mathrm{~h}$ under constant stirring. The reaction mixture was then dialyzed against water for 4 days and freeze-dried to obtain DBCO-conjugated chondroitin sulfate (CS-DBCO). The product was stored at $-20^{\circ} \mathrm{C}$ until use. The product was characterized by a combination of Fourier transform infrared spectroscopy (FTIR) and proton nuclear magnetic resonance ( $\left.{ }^{1} \mathrm{HNMR}\right)$ spectroscopy. The peaks in attenuated total reflection (ATR) FTIR spectra at $1,612 \mathrm{~cm}^{-1}$ due to $\mathrm{C}=\mathrm{O}$ stretching and $1,559 \mathrm{~cm}^{-1}$ due to $\mathrm{N}-\mathrm{H}$ deformation in the CS spectrum were shown to be shifted to 1,648 and $1,569 \mathrm{~cm}^{-1}$ in the CS-DBCO spectrum, respectively, indicating the presence of new amide bonds formed via the reaction between the carboxylic acid group of CS and the amine group of DBCO. In addition, peaks were observed at 1,480 and $1,441 \mathrm{~cm}^{-1}$, which represented the aromatic $\mathrm{C}=\mathrm{C}$ stretching in the rings of $\mathrm{DBCO}$ (Supplementary Figure S1). The successful conjugation of DBCO to CS was further confirmed by ${ }^{1} \mathrm{HNMR}$ where the spectrum showed the appearance of aromatic protons from DBCO at 7.34-7.44 ppm. The degree of $\mathrm{DBCO}$ conjugation was calculated by taking the ratio of area under the curve for the aromatic protons of $\mathrm{DBCO}$ at 7.34-7.44 ppm to the $-\mathrm{CH}_{3}$ protons of the $-\mathrm{NHCOCH}_{3}$ groups of $\mathrm{CS}$ at $1.9 \mathrm{ppm}$ and found to be $39 \pm 2 \%$ with respect to the dimeric sugar unit of CS (Supplementary Figure S2).

For collagen azide, $1 \mathrm{mg}$ of collagen type I (Corning, 354236) and $500 \mu \mathrm{l}$ of azide-polyethylene glycol-NHS) (Click Chemistry Tools, AZ103) were dissolved in $10 \mathrm{ml}$ PBS each. The reaction was performed by mixing the solutions under constant stirring for $3 \mathrm{~h}$ at $0-4^{\circ} \mathrm{C}$. The reaction mixture was then dialyzed against water at $4^{\circ} \mathrm{C}$ for 3 days. The product was freeze-dried and stored at $-20^{\circ} \mathrm{C}$ until use. The product was characterized via FTIR spectroscopy where the spectra revealed a sharp peak at $2,141 \mathrm{~cm}^{-1}$ characteristic to the $\mathrm{N} \equiv \mathrm{N}$ stretching frequency of the azide functional group (Supplementary Figure S3).

\section{Collagen Functionalization of the Membrane}

The PDMS membrane in the bonded devices was treated with corona treater (ETP, BD-20AC) for $1 \mathrm{~min}$ to plasma-activate the surface. Approximately $100 \mu \mathrm{l}$ of $2 \%$ (v/v) (3-aminopropyl)trimethoxysilane (APTMS) (Sigma, 281778) in 100\% ethanol was introduced into the cell culture chamber, and the devices were incubated for $60 \mathrm{~min}$ at room temp and washed with distilled water. Meanwhile, $5 \mathrm{mg}$ of CS-DBCO was dissolved in $1 \mathrm{ml}$ of PBS and reacted with $5 \mathrm{mg}$ of EDC for $15 \mathrm{~min}$, followed by $2.1 \mathrm{mg}$ of NHS to convert CS-DBCO into CS-DBCO-NHS ester. The devices were incubated with this activated CS-DBCO-NHS ester at $37^{\circ} \mathrm{C}$ for overnight to covalently immobilize CS-DBCO on the PDMS surface. The next day, the devices were washed $2-3$ times with distilled water, and $10 \mu \mathrm{g} / \mathrm{ml}$ of collagen-azide solution in PBS was introduced into the devices. The devices were incubated overnight to immobilize collagen onto the PDMS surface via a strain-promoted azide-alkyne cycloaddition (SPAAC) reaction between the azide group of collagen zide and the DBCO group of surface-bound CS-DBCO. The devices were washed with PBS before culturing cells.

\section{Isolation and Culture of Human Primary AT2 Cells}

Healthy human lungs were procured through the BioRepository and Precision Pathology Center at Duke University in accordance with institutional procedures (Duke University Pro00082379-“Human Lung Stem Cells"; exempt research as described in 45 CFR 46.102(f), 21 CFR 56.102(e) and 21 CFR 812.3(p) which satisfies the Privacy Rule as described in 45CFR164.514). Human lung dissociation was performed as described previously (Zacharias et al., 2018). Briefly, approximately $2 \mathrm{~g}$ human lung tissue was cut into small pieces and incubated with $30 \mathrm{ml}$ of enzyme mixture (collagenase type I (Gibco, 17100-017): $1.68 \mathrm{mg} / \mathrm{ml}$, dispase (Corning, 354235): 5 U/ $\mathrm{ml}$, DNase (Thermo Fisher Scientific, 10104159001): $10 \mathrm{U} / \mathrm{ml}$ ) at $37^{\circ} \mathrm{C}$ for $1 \mathrm{~h}$ with continuous rotation. The cells were filtered through a $100-\mu \mathrm{m}$ cell strainer and rinsed with DMEM/F12 containing $10 \%$ FBS and anti-anti through the strainer. The sample was centrifuged at $450 \mathrm{~g}$ for $10 \mathrm{~min}$, and the cell pellet was resuspended in red blood cell lysis buffer for $10 \mathrm{~min}$, washed with DMEM/F12 containing 10\% FBS, and filtered through a $40-$ $\mu \mathrm{m}$ strainer. Total cells were centrifuged at $450 \mathrm{~g}$ for $5 \mathrm{~min}$ at $4^{\circ} \mathrm{C}$ and the cell pellet was processed for alveolar type 2 cell (AT2s) purification. AT2s were isolated by magnetic-activated cell sorting (MACS) or fluorescence-activated cell sorting (FACS)based protocols as described previously (Katsura et al., 2020). Approximately 2-10 million total human lung cells were resuspended in MACS buffer and incubated with Human TruStain FcX (Biolegend, 422032) for $15 \mathrm{~min}$ at $4^{\circ} \mathrm{C}$, followed by incubation with HTII-280 (Terrace Biotech, TB-27AHT2-280) (1:60 dilution) antibody for $1 \mathrm{~h}$ at $4^{\circ} \mathrm{C}$. The cells were washed twice with MACS buffer and incubated with anti-mouse IgM microbeads for $15 \mathrm{~min}$ at $4^{\circ} \mathrm{C}$. The sample was loaded into the LS column (Miltenyi Biotec), and cells were collected magnetically. For FACS based purification of human AT2s, the total lung cell pellets were resuspended in MACS buffer and the EpCAMpositive population was purified using microbeads according to the manufacturer's instructions (Miltenyi Biotec, 130-061101). CD326-positive cells were stained with HTII-280 and LysoTracker (Thermo Fisher Scientific, L7526) at $37^{\circ} \mathrm{C}$ for $25 \mathrm{~min}$, followed by incubation with secondary antibody Alexa anti-mouse IgM-488 (Thermo Fisher Scientific, 10680) for $10 \mathrm{~min}$ at $37^{\circ} \mathrm{C}$, washed twice and sorted using a FACS Vantage SE and SONY SH800 S. The cells were expanded as alveolospheres in growth factor reduced Matrigel (Corning, 354230) as described previously (Katsura et al., 2020), using Advanced DMEM/F12 medium containing $10 \mu \mathrm{M}$ SB431542 (Abcam, 120163), $3 \mu \mathrm{M}$ CHIR99021 (Tocris, 4423), $1 \mu \mathrm{M}$ BIRB796 (Tocris, 5989), $10 \mu \mathrm{M}$ Y27632 (Selleckchem, S1049) (for first 4 days of culture), $50 \mathrm{ng} / \mathrm{ml}$ Human EGF (Gibco, PHG0313), $10 \mathrm{ng} / \mathrm{ml}$ Human FGF10 (Biolegend, 559304), 
$5 \mu \mathrm{g} / \mathrm{ml}$ Heparin (Sigma, H3149), 1X B27 supplement (Thermo Fisher Scientific, 17504044), 1X Antibiotic-Antimycotic (Thermo Fisher Scientific, A5955), 15 mM HEPES, 1X Glutamax (Thermo Fisher Scientific, 35050061), and 1.25 mM N-Acetyl-L-Cysteine (Sigma, A9165).

\section{Culture of Human Induced Pluripotent Stem Cell (hiPSC)-Derived AT2 Cells (iAT2 Cells)} IPSCs-derived human alveolar type 2 cells (iAT2s) (differentiated from the SPC2-ST-B2 iPSC line) were expanded as alveolospheres in growth factor reduced Matrigel (Corning, 354230) as described elsewhere (Jacob et al., 2019). The iAT2s were maintained in IMDM medium containing 25\% Ham's F12 (Cellgro, 10-080-CV), 1\% B27 supplement, 0.5\% N2 supplement, 0.05\% BSA (Invitrogen, 15260037), $200 \mathrm{ng} / \mathrm{ml}$ Primocin (Invivogen, NC9141851), 1X GlutaMAX, $50 \mu \mathrm{g} / \mathrm{ml}$ ascorbic acid (Sigma, A4544), $0.45 \mathrm{mM}$ monothioglycerol (Sigma, M6145), $3 \mu \mathrm{M}$ CHIR99021, $10 \mathrm{ng} / \mathrm{ml}$ rhKGF (R\&D, 251-KG010), $50 \mathrm{nM}$ Dexamethasone (Sigma, D4902), $10 \mu \mathrm{M}$ Y27632 (for first 3 days of culture), $0.1 \mathrm{mM} 8$-bromoadenosine $3^{\prime}, 5^{\prime}$-cyclic monophosphate sodium salt (Sigma, B7880), and $0.1 \mathrm{mM} \mathrm{3-}$ isobutyl-1-methylxanthine (Sigma, I5879).

\section{Culture of MLE-12 and H441 Cell Lines}

MLE-12 cells were maintained in HITES medium consisting of DMEM/F12 (ATCC, 30-2006), 2\% fetal bovine serum (FBS), $0.005 \mathrm{mg} / \mathrm{ml}$ insulin, $0.01 \mathrm{mg} / \mathrm{ml}$ transferrin (Fitzgerald, 31CCH1026), $30 \mathrm{nM}$ sodium selenite (Santa Cruz, 253595), $10 \mathrm{nM}$ hydrocortisone (Sigma, H0888), $10 \mathrm{nM} \quad \beta$-estradiol, $10 \mathrm{mM}$ HEPES (Gibco, 15630106), 2 mM L-glutamine (Gibco, 25030081), and 1\% Pen-Step (Gibco, 15140122). H441 cells were maintained in RPMI-1640 (ATCC, 30-2001) medium supplemented with 10\% FBS and $1 \%$ Pen-Strep.

\section{Cell Seeding Within the Device}

For seeding hAT2s and iAT2s into the devices, alveolosphere dissociation was carried out by incubating the cultures in $2 \mathrm{mg} / \mathrm{ml}$ dispase for $30 \mathrm{~min}$ to release the alveolospheres from the Matrigel matrix. This was followed by centrifugation at $200 \mathrm{~g}$ for $4 \mathrm{~min}$ and resuspension of the alveolospheres in $0.05 \%$ Trypsin-EDTA for $5 \mathrm{~min}$. The cell suspension was centrifuged at $300 \mathrm{~g}$ for $5 \mathrm{~min}$ and the cells were resuspended in their medium before counting. For cell lines, the cells were detached from the culture plate using $0.25 \%$ trypsin-EDTA, centrifuged, and resuspended in medium before counting.

Single cells were suspended in their corresponding medium at a concentration of $2 \times 10^{5}$ cells $/ \mathrm{ml} ; 100 \mu \mathrm{l}$ of the cell suspension was perfused into the fluidic chamber of the device. The cell-loaded devices were left undisturbed $(2 \mathrm{~h}$ for cell lines and $6 \mathrm{~h}$ for hAT2s and iAT2 cells) to allow the cells to adhere to the membrane before they were connected to the syringe pump to start the perfusion. The cells were cultured in a submerged condition within the device. A tubing was connected from the fluidic outlet into an Eppendorf tube to collect the perfusate. Twenty-four hours after cell seeding, the air pump was connected to the pneumatic inlet of the devices to induce breathing-like motion.

\section{Immunofluorescence Staining and Quantification}

The fluidic layer was separated from the pneumatic layer, and the cover slip was removed from the top. The cells were washed three times with PBS and fixed with 4\% PFA for $15 \mathrm{~min}$. The cells were washed again with PBS and treated with a permeabilization solution for $15-20 \mathrm{~min}$ (PBS/0.1\% Triton-X). After permeabilization, the cells were blocked using $5 \%$ normal donkey serum in $1 \%$ BSA. Cells were then treated with anti-prosurfactant protein $\mathrm{C}$ primary antibody (Sigma, AB3786) for overnight at $4^{\circ} \mathrm{C}(1: 150)$. The next day, the cells were washed 3 times with PBS and incubated with the secondary antibody (anti-rabbit Alexa Flour 647, 1:200) for $1 \mathrm{~h}$. The staining solution was then removed, Hochest $(1: 1,000)$ was added, and the mixture was incubated for $4 \mathrm{~min}$. Finally, cells were washed and imaged using a Keyence BZ microscope. Mean fluorescence intensity was quantified using ImageJ. Another set of cultures were stained with phalloidin (1:200) for $1 \mathrm{~h}$ and with Hochest $(1: 1,000)$ for $4 \mathrm{~min}$. The cells were washed, and images of various locations within the membrane were acquired. OrientationJ plugin (Püspöki et al., 2016) within ImageJ was used to analyze the images.

\section{Surfactant Protein-A ELISA}

For Surfactant Protein-A (SP-A) ELISA experiments, devices were seeded with $\mathrm{H} 441$ cells, which were allowed to grow to confluence for 3 days before exposing them to breathing-like motions. Just before the start of the experiments, the outlet reservoir was emptied, and the flow rate was reduced to $5 \mu \mathrm{l} / \mathrm{h}$ to concentrate the secreted surfactant. After $24 \mathrm{~h}$ of breathing, it was visually confirmed under a microscope that the cell layer had not detached during the experiment. Perfusate collected in the outlet reservoir was used for surfactant protein-A ELISA using the SP-A kit (Biovender, RD191139200R) according to the manufacturer's instructions.

\section{Determining Concave Volume and Compliance Curves}

The concave volume of the membrane in response to applied air pressure (0-50 mbar) was calculated using COMSOL. The side view of the computational model of the membrane in stretched position was projected onto a $2 \mathrm{D}$ plane. The boundary of the membrane was traced to obtain the spatial points. A 6-order polynomial curve was fitted onto the points to obtain the equation for the curve. The volume encompassed was calculated by integrating the equation in three dimensions using Wolfram Alpha. This was done for membranes of different thicknesses $250 \mu \mathrm{m}$ and $1,000 \mu \mathrm{m}$ subjected to different pressures. The obtained volumes were plotted against the corresponding applied pressure to obtain the compliance plot.

\section{Transpulmonary Pressure Setup}

To introduce hydrostatic pressure, the outlet of the fluidic microchannels was blocked using knotted PTFE tubing. A 10$\mathrm{ml}$ syringe was filled with cell culture medium and its plunger was removed to expose the media to the atmosphere. A lid was placed at the end of the syringe to reduce the chances of contamination. 

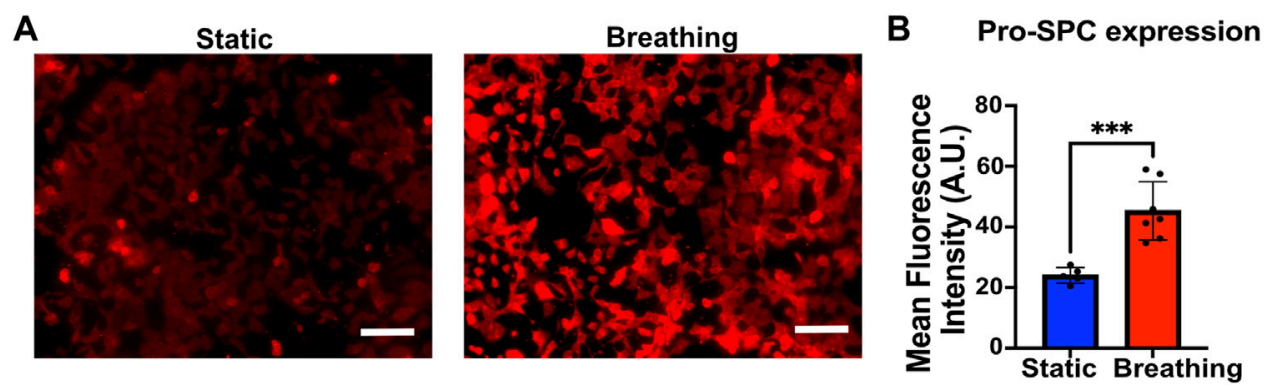

FIGURE 2 | (A) Immunofluorescent staining of Pro-SPC (red) of MLE-12 cells cultured under static and breathing conditions. (B) Quantification of the fluorescent intensity reveals that cells exposed to breathing-like motions express significantly higher pro-SPC. Each data point is an average of fluorescence intensity measurement from 6 to 11 images per independent device ( $N=5$ for static and $N=7$ for breathing). Scale: $100 \mu \mathrm{m}$.

Tubing was connected from the syringe to the inlet of the fluid microchannels of the device. To generate positive hydrostatic pressure of $50 \mathrm{mbar}$, the syringe was placed $50 \mathrm{~cm}$ above the height of the device throughout the experiment.

\section{Live-Dead Analysis}

A viability/cytotoxicity kit (Thermo Fisher Scientific, L3224) was used to determine cell viability. Briefly, media was aspirated from the fluidic layer of the device, and the cells were washed with PBS. Then $100 \mu \mathrm{l}$ of solution containing $0.05 \%$ calcein AM and $0.2 \%$ ethidium homodimer-1 was introduced into the device. The cells were incubated in the solution for $30 \mathrm{~min}$ before washing them with PBS and imaging them.

\section{Statistics}

Statistical analysis was performed on GraphPad Prism 9. An unpaired $t$-test was used to compare the mean fluorescent intensity in Figure 2 and Figure 6; the cell shape in Figure 6 and the SP-A levels in Supplementary Figure S5. For comparison of mean fluorescence intensity of cells cultured on 250- and $1,000-\mu \mathrm{m}$-thick membranes across center and edge, respectively, 2-way repeated measures ANOVA followed by multiple comparisons was used, with "center" and "edge" values being the repeated measures for each device. $\mathrm{N} \geq 3$ independent devices per experimental group were used across all experiments. $p$-values $<0.05$ were considered statistically significant.

\section{RESULTS AND DISCUSSION}

\section{Device Fabrication and Cell Culture}

The device consists of a bottom pneumatic layer and a top fluidic layer separated by a thin PDMS membrane (Figure 1C). The top layer consists of an inlet that diverges into an array of microchannels leading to a cylindrical cell culture chamber. This chamber is lined with a thin membrane at the base. Another array of microchannels connects the cell culture chamber to the device outlet. These channels are used for cell seeding and medium perfusion. In the bottom layer, the inlet diverges into an array of microchannels that lead to a cylindrical chamber whose ceiling is formed by the thin membrane and whose base is capped by a cover glass. The bottom layer is devoid of any outlets so that the device can be subjected to a pressure waveform to induce breathing-like movements. The PDMS membrane facing the fluid side was functionalized with collagen type I to promote cell attachment (Figure 1D). When subjected to a positive pressure in the bottom layer, the membrane concaves downward, which induces stretching of the membrane (Figure 1E). Applying a pressure waveform via the air pump facilitates cyclic stretching of the membrane, thus mimicking the breathing movements of alveoli (Supplementary Movie S1). Digital images of the device and of the setup are shown in Figure 1F and Supplementary Figure S4, respectively. Cells were perfused into the device via the inlet channel and allowed to adhere before introducing continuous perfusion of medium. The cells were cultured for $24 \mathrm{~h}$ before subjecting them to breathing-like movements. The device supported culture of alveolar epithelial cell lines, human primary alveolar epithelial cells (hAT2s) and human induced pluripotent (hiPSC)-derived alveolar epithelial cells (iAT2s).

\section{Effect of Breathing-Like Motion on Surfactant Production}

To study the effect of breathing-like motion-mediated active mechanical cues on alveolar cell functions, the epithelial cells within the device were subjected to cyclic stretching. The MLE-12 cells were subjected to breathing-like motions for $24 \mathrm{~h}$, following which they were fixed and stained for surfactant protein- $C$ (proSPC). Cells that were exposed to breathing-like motion expressed significantly higher levels of pro-SPC than cells cultured in static conditions (Figures 2A, B). Higher surfactant production in breathing cultures was further confirmed by H441 cells. As shown in Supplementary Figure S5, the cells subjected to dynamic breathing showed more secreted surfactant protein-A (SP-A). These results are in line with previous reports which showed increased surfactant production in response to cells subjected to stretching (Sanchez-Esteban et al., 1998; Torday and Rehan, 2002). The effect of mechanical cues on surfactant production has also been established in in vivo studies where mechanical ventilation-induced stretch has been reported to increase surfactant production in rat lungs (Martinez et al., 2004). 

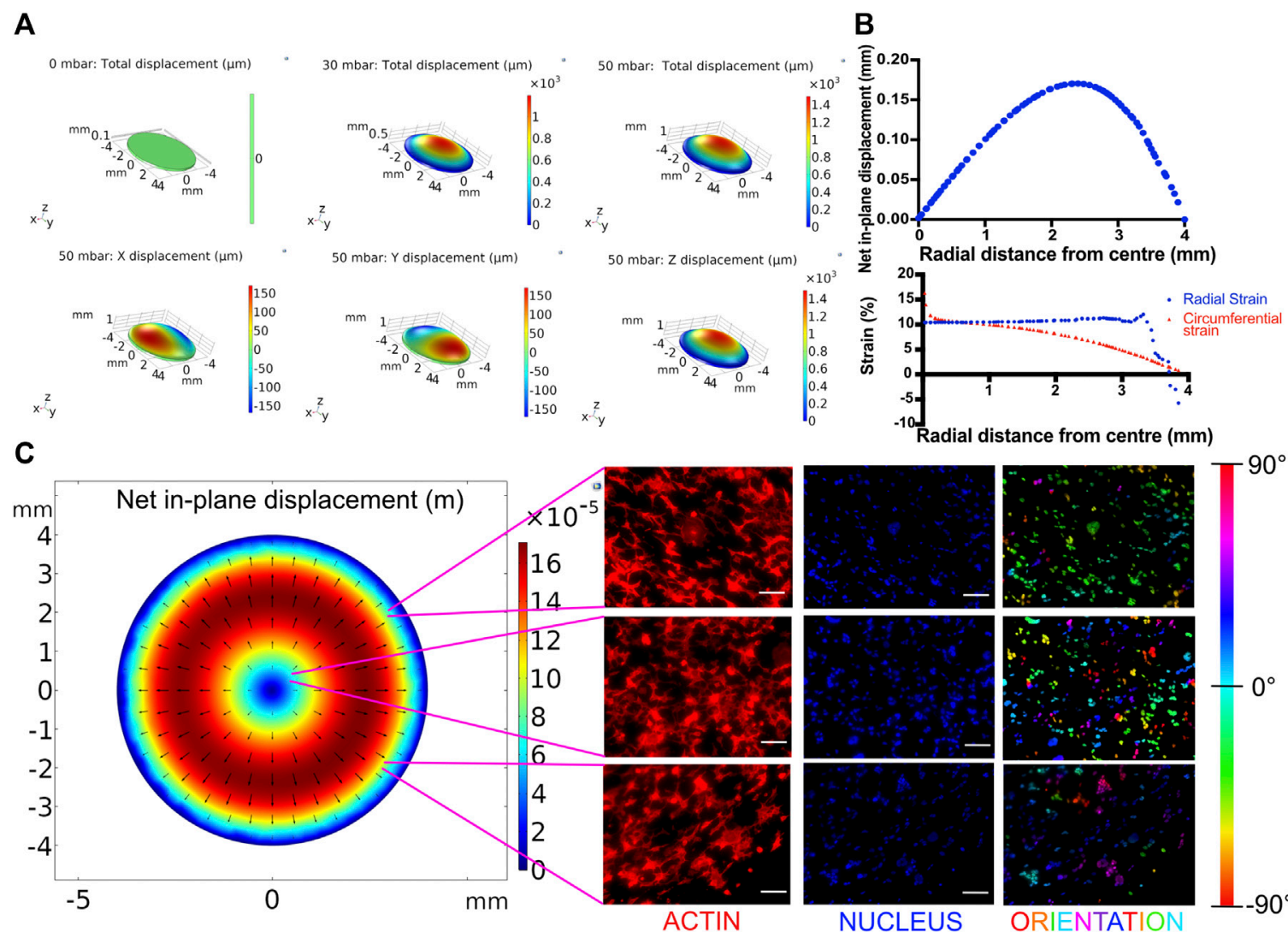

NUCLEUS

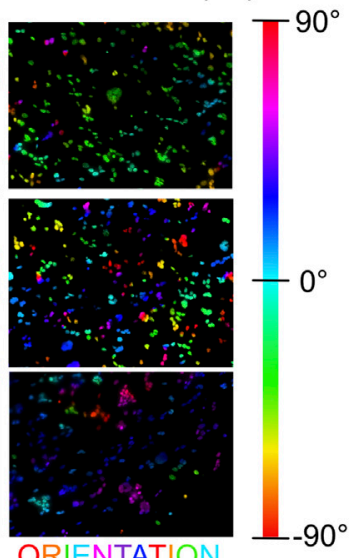

FIGURE 3 | (A) Displacement profiles of the breathing membrane subjected to various peak pressures. (B) In-plane displacement, radial strain and circumferential strain profile of the cell culture membrane at 50 mbar. (C) Effect of spatial strain heterogeneity of the cell culture substrate on cell alignment. Left: COMSOL computed inplane displacement of the cell culture membrane. Right: Cellular alignment of MLE-12 cells was visualized by phalloidin (first column), and nucleus (second column) staining and cellular alignment at different locations in breathing devices was quantified using nuclear orientation (third column) where color of the nuclei in the third column represents their angle of alignment. Cells at the center of the membrane align randomly while those away from center align perpendicular to the radius. Scale: $100 \mu \mathrm{m}$.

\section{Breathing-Induced Heterogeneous Strain Profile and Its Effect on Cell Shape}

While dynamic stretching was found to promote surfactant production overall, we next analyzed the out-of-plane stretching-induced heterogeneous strain profile and its effect on the cells. Toward this, the membrane deformation during cyclic stretch was modeled in COMSOL as detailed in the experimental section. The effect of applied pressure on the membrane displacement field was determined by mapping the strain profile (Figure 3A). Using the displacement field, radial and circumferential strains were calculated at a peak pressure of 50 mbar. This pressure was chosen as it falls within the range of air pressure in the human lung during breathing and also results in physiological levels of strain (Roan and Waters, 2011). At this pressure, the in-plane displacement increases with increasing radial distance from the center $(r)$ and gradually decreases, peaking at around $\mathrm{r}=2.5 \mathrm{~mm}$ (Figure 3B). The circumferential strain was found to gradually decrease from 17 to $0 \%$ with increasing radial distance from the center. The radial strain largely remains constant at around $10 \%$ until a sharp decline after $r>3 \mathrm{~mm}$ due to the membrane being constricted at the edges (Figure 3B). MLE-12 cells on the membrane responded to the radial strain heterogeneity and exhibited a differential alignment. Specifically, at the center of the membrane, the cells were aligned randomly, while away from the center, they were aligned perpendicular to the direction of the major strain (i.e., the direction of radial displacement) (Figure 3C). In addition to epithelial cells, we have also examined the effect of strain heterogeneity on NIH 3T3 cells as fibroblasts are known to be highly sensitive to mechanical cues, including cyclic strain (Neidlinger-Wilke et al., 2002). Akin to epithelial cells, the fibroblasts displayed strain profile-dependent cell alignment, where cells away from the center aligned perpendicular to the direction of major strain, while those at the center were randomly aligned (Supplementary Figure S6). The strain-dependent alignment was more pronounced in the case of fibroblasts than in the epithelial cells, which is most likely attributed to the propensity of fibroblasts to polarize in cultures and acquire elongated morphology. 


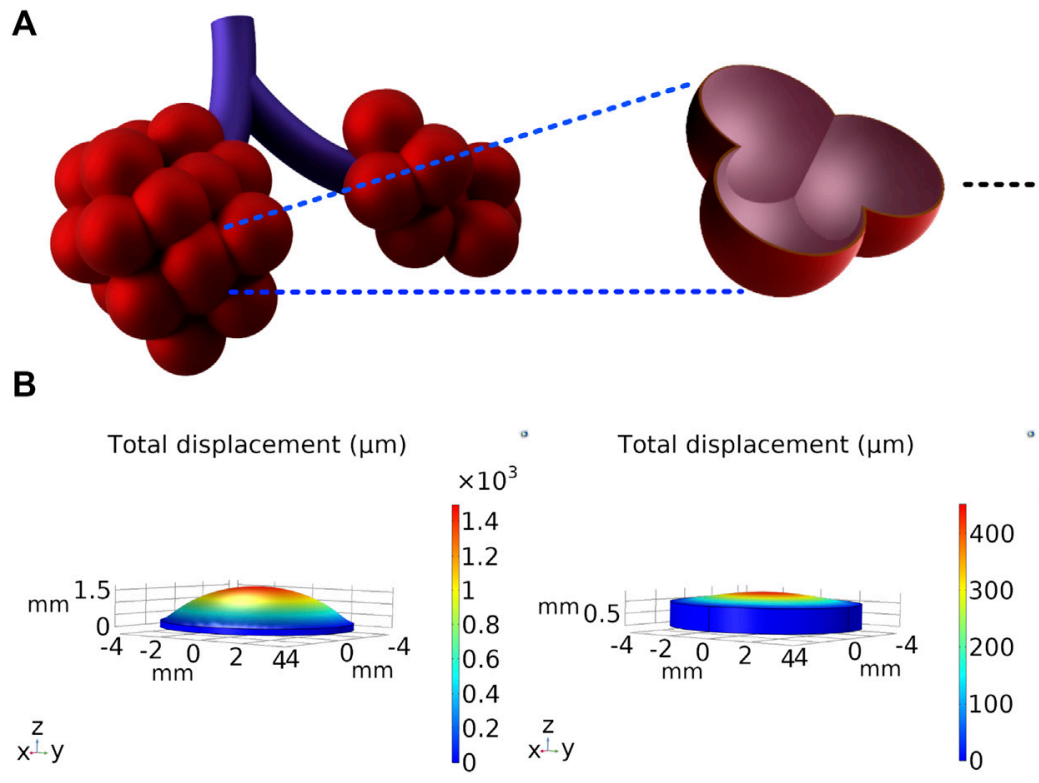

D
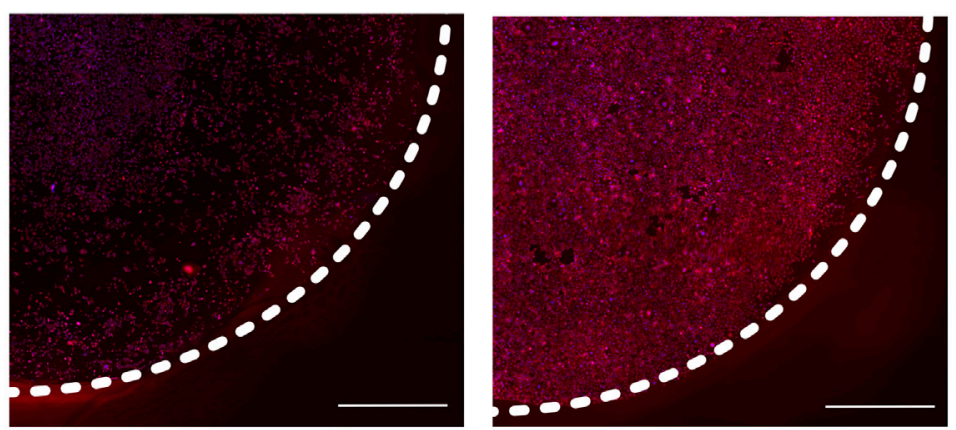

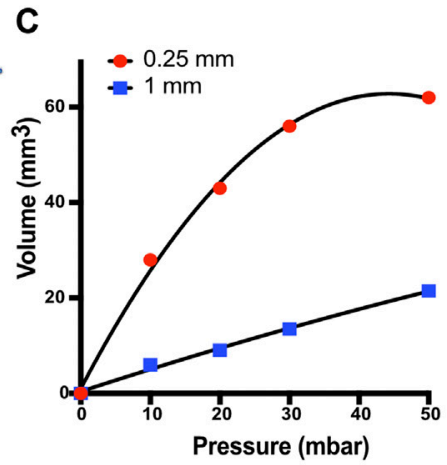

E

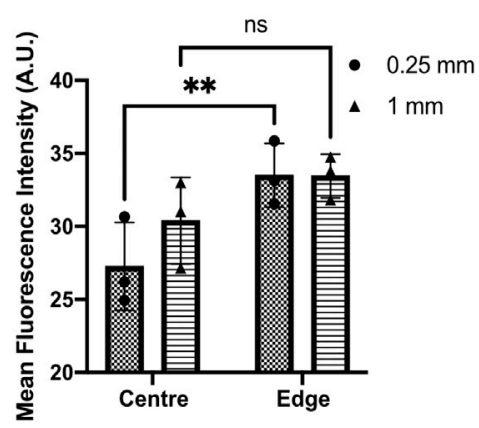

FIGURE 4 | (A) Schematic depicting the change in alveolar wall thickness as a result of interstitial wall thickening. (B) Displacement profiles of membranes with 250 and 1,000 $\mu \mathrm{m}$ thickness subjected to 50 mbar pressure (C) Pressure-volume compliance curves for membranes with 250 and 1,000 $\mu \mathrm{m}$ thickness when subjected to a breathing-like motion (D) Immunofluorescent staining for Pro-SPC (red) and nucleus (blue) in MLE-12 cells cultured on $250-\mu m$ (left) and 1,000- $\mu \mathrm{m}$ (right)-thick membranes and $(\mathbf{E})$ its quantification at center $(r<3 \mathrm{~mm})$ and edge $(3 \mathrm{~mm}<\mathrm{r}<4 \mathrm{~mm}$ ) of the device. $\mathrm{N}=3$ where each data point is an average of fluorescence intensity measurement from 7 to 12 images per independent device. White-dotted line represents the boundary of the membrane Scale: $1 \mathrm{~mm}$.

\section{Modeling Matrix Compliance}

Changes in tissue compliance are a key characteristic of various lung diseases. For example, diseases like pulmonary fibrosis are characterized by alveolar wall thickening due to excessive accumulation of extracellular matrix and an increase in tissue stiffness, resulting in lowered compliance (Figure 4A). We have modeled the lowered tissue compliance by increasing the thickness of the membrane from 250 to $1,000 \mu \mathrm{m}$. With increasing thickness, the membrane will offer higher resistance to the same pressure profile than a $250-\mu \mathrm{m}$ membrane, which results in less expansion/contraction and thereby a different breathing pattern (Supplementary Movie S2). The pulmonary compliance, which is expressed as the change in lung volume in response to a change in pressure $\left(\frac{\Delta V}{\Delta P}\right)$, was calculated by computationally measuring the changes in the concave volume of the membrane as a function of pressure during breathing-like movements (Figures 4B,C). We chose a membrane thickness of
250 and $1,000 \mu \mathrm{m}$ as they offer $\sim 2.8$ fold difference in volume at peak pressure, which is in the range of volume differences observed between healthy and fibrotic human lungs (Harris, 2005).

We examined the membrane compliance-mediated strain profile for an applied peak pressure of 50 mbar. As expected, the high compliance membrane (i.e., $250-\mu \mathrm{m}$ membrane) encountered a significantly higher strain heterogeneity than the low compliance membrane $(1,000 \mu \mathrm{m}$ membrane). This is attributed to the lower resistance imposed by the $250 \mu \mathrm{m}$ membrane, permitting higher deformation (Figure 4B). To examine the effect of cell response to the altered matrix compliance, MLE-12 cells were cultured in the device with membranes of thickness $250 \mu \mathrm{m}$ and $1,000 \mu \mathrm{m}$ and analyzed after subjecting them to $24 \mathrm{~h}$ of breathing-like motion. A significant difference in cell number was observed between the two, with the 1,000- $\mu \mathrm{m}$ membrane that experiences lower strains 
A
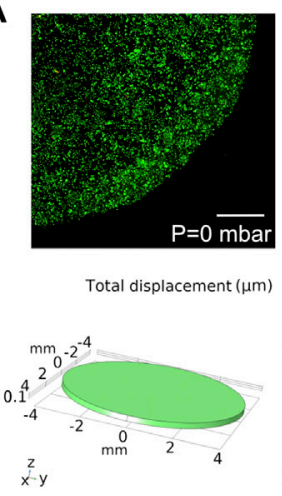

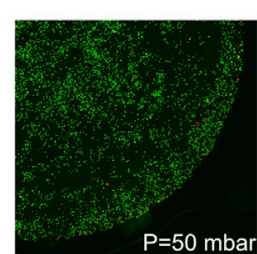

Total displacement $(\mu \mathrm{m})$

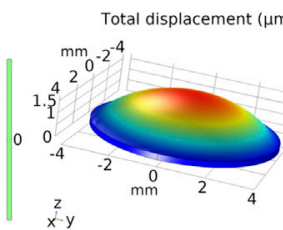

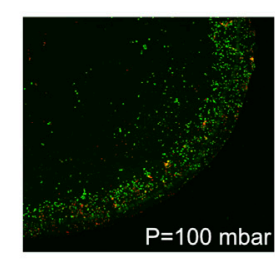

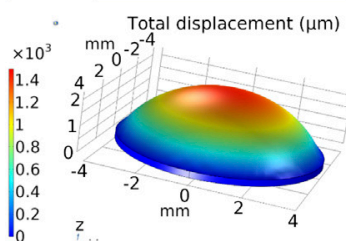

B

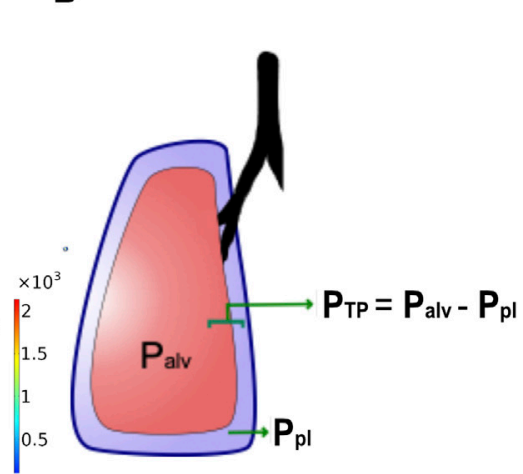

C

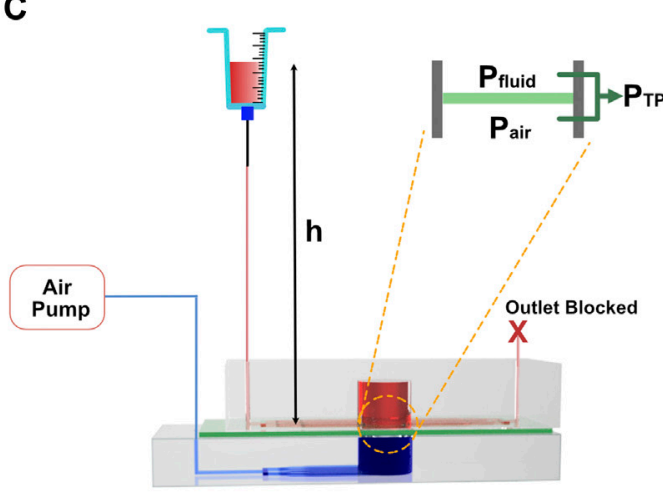

D
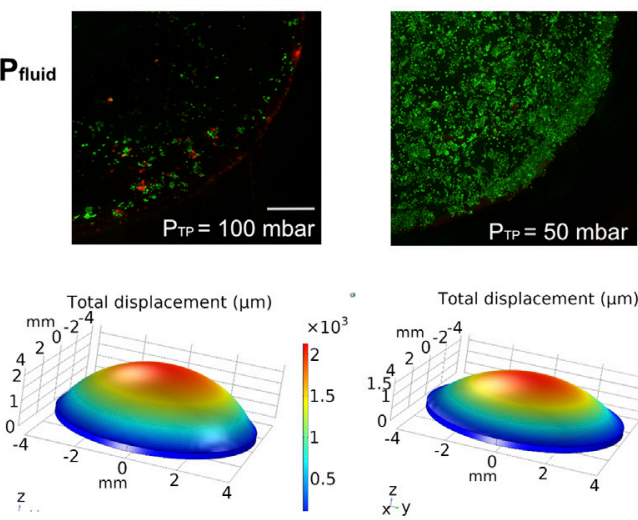

$\times 10^{3}$
1.4
1.2
1
0.8
0.6
0.4
0.2
0

FIGURE 5 | (A) COMSOL modeling and corresponding cell experiments for studying the effect of volutrauma as a result of applied air pressure of 0 mbar, 50 , and 100 mbar. Higher air pressure leads to higher concave volume. Viability of MLE-12 cells was determined using live-dead assay. Live cells are stained green while the dead cells are stained red. (B) Schematic depicting transpulmonary pressure in a lung. $\mathrm{P}_{\mathrm{TP}}, \mathrm{P}_{\mathrm{alv}}$, and $\mathrm{P}_{\mathrm{pl}}$ are transpulmonary pressure, air pressure in the alveoli and pleural pressure, respectively. (C) Schematic showing the modeling of transpulmonary pressure in the device. $P_{\text {air }}$ and $P_{\text {fluid }}$ represent the air pressure and hydrostatic pressure in the device. (D) COMSOL modeling and corresponding cell experiment for studying barotrauma as a result of applied transpulmonary pressure of 50 and 100 mbar. Scale: $1 \mathrm{~mm}$.

showing the presence of more cells (Figure 4D). Furthermore, the strain-dependent spatial variation in cell number was prominently observed on the $250-\mu \mathrm{m}$ membrane, where the strain varies spatially over a wider range. Specifically, areas with high displacement exhibited lower cell numbers. On the contrary, such regional differences in cell number were not observed in the 1,000- $\mu \mathrm{m}$ membrane. Concomitant with these findings, spatial differences in surfactant production were also observed between the two conditions, as evident from the quantification of pro-SPC immunofluorescence intensity (Figure 4D).

\section{Modeling Transpulmonary Pressure and Ventilator-Induced Lung Injury}

Ventilator-induced lung injury (VILI) is thought to be closely related to strain heterogeneity in the lung, such that the injury occurs at high-strain regions (Beitler et al., 2016). The described fluidic-pneumatic platform is thus an ideal platform to model VILI. The two most commonly observed ventilator-induced lung injuries are volutrauma and barotrauma, which are closely related and result from alveolar overdistension caused by high tidal volumes and high transpulmonary pressure, respectively. To model volutrauma, the peak pressure of the air pressure waveform was increased from 50 to $100 \mathrm{mbar}$ to generate increased concave volume and overdistension of the membrane. The concave volume for 50 and $100 \mathrm{mbar}$ was 62.46 and $101.926 \mathrm{~mm}^{3}$, respectively. As evident from the live/ dead assay for MLE-12 cell cultures under these conditions, the increased pressure and the associated overdistention caused cell death and/or detachment of the cells (Figure 5A). At higher pressures/volumes, the effect of spatial strain heterogeneity on cell number was amplified, as seen in the case of $100 \mathrm{mbar}$, where more cells were found to be at the edges $(3 \mathrm{~mm}<\mathrm{r}<4 \mathrm{~mm}$ ) than in the center $(\mathrm{r}<3 \mathrm{~mm})$. Among the two pressures imposed, the devices exposed to 50 mbar air pressure had higher cell numbers at the edges than those exposed to 100 mbar. Comparing the experimental observations with the corresponding strain derived from COMSOL simulation suggests that strains above $\sim 18 \%$ could be detrimental to the cells. 

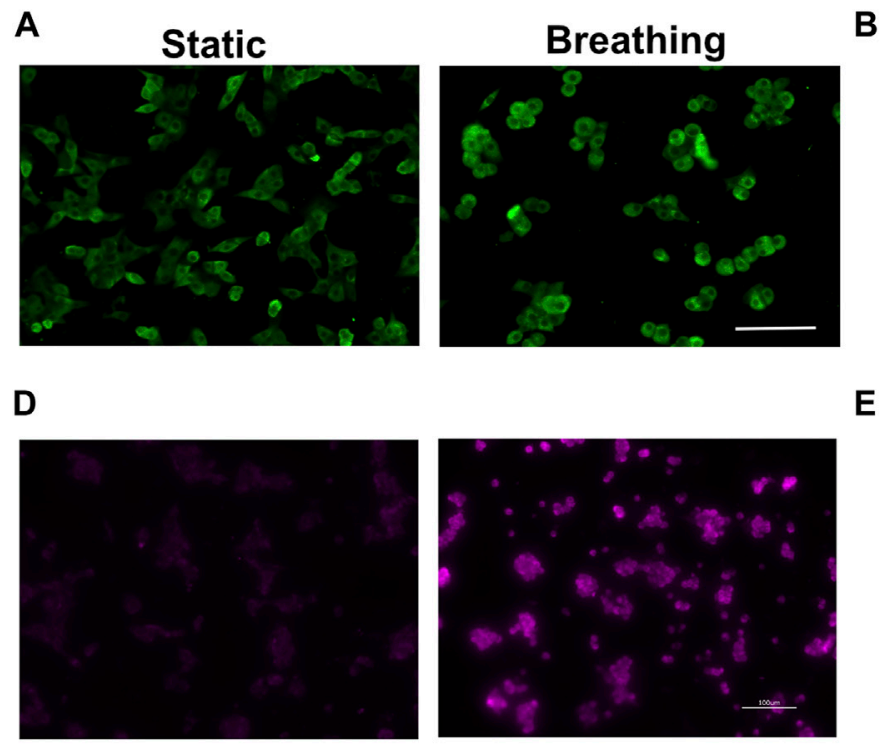
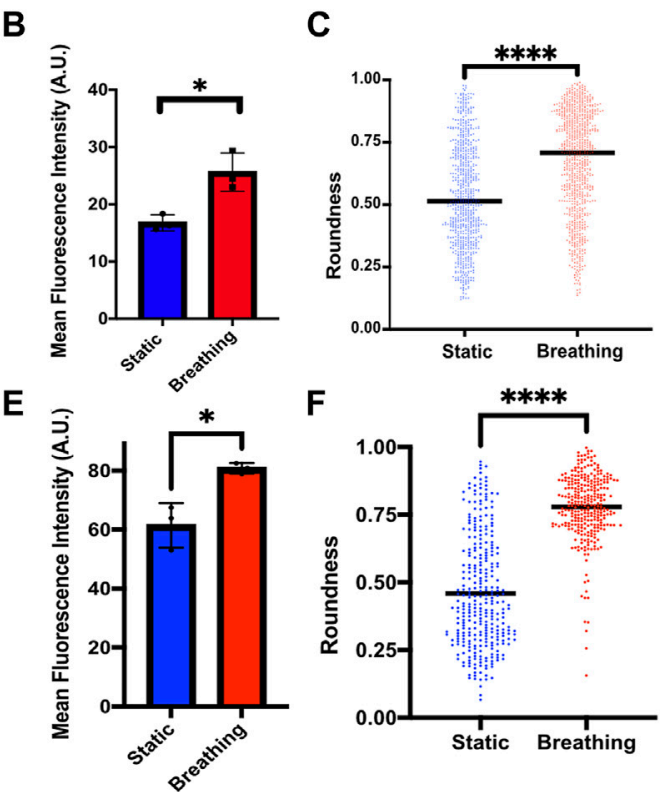

FIGURE 6 | (A) Immunofluorescence staining of Pro-SPC (green) in primary human AT2 cells cultured under static and breathing conditions and (B) its quantification. $\mathrm{N}=3$ where each data point is an average of fluorescence intensity measurement from 8 to 15 images per independent device. (C) Quantification of cell morphology in static and breathing conditions. (D) Immunofluorescent staining of Pro-SPC (magenta) in iAT2 cells cultured under static and breathing conditions and (E) its quantification. $\mathrm{N}=3$ where each data point is an average of fluorescence intensity measurement from 9 to 13 images per independent device. (F) Quantification of cell morphology in static and breathing conditions. Scale: $100 \mu \mathrm{m}$.

To model the lung transpulmonary pressure (alveolar air pressure-pleural fluid pressure) (Figure 5B), we have made a slight modification to the device to incorporate pleural fluid pressure. This was achieved by blocking the outlet of the media channels and replacing the syringe pump at the inlet with an open-ended syringe whose height can be easily varied (Figure 5C). The hydrostatic pressure developed in the chip by increasing the height of the syringe was used to mimic the pleural pressure, which applies a force on the membrane opposite to that of the air pressure, thus allowing us to define the transpulmonary pressure of the device as follows:

$$
P_{T P}=P_{\text {air }}-P_{\text {fluid }}=P_{\text {air }}-\rho g h,
$$

where $\mathrm{P}_{T P}$ is the transpulmonary pressure of the device, $\mathrm{P}_{\text {air }}$ is the applied peak pressure through the air pump, $P_{\text {fluid }}$ is the hydrostatic pressure on the fluid side of the device, $\rho$ is the density of the medium, $g$ is the gravitational constant, and $h$ is the height of the syringe above the device.

Leveraging this approach, we tested two conditions of varying transpulmonary pressure (50 and $100 \mathrm{mbar}$ ). To generate transpulmonary pressures of $50 \mathrm{mbar}$ and $100 \mathrm{mbar}$, the syringe height was raised to $50 \mathrm{~cm}$ above the device height or kept at device height, respectively, while maintaining the applied air pressure at 100 mbar in both conditions. After $24 \mathrm{~h}$ of breathing, devices that were subjected to a transpulmonary pressure of 50 mbar showed minimal cell loss, despite the high air pressure encountered (Figure 5D). This is due to the hydrostatic pressure from the medium in the syringe opposing the high air pressure supplied from the air pump, which is akin to pleural fluid pressure opposing the high air pressure in the lung. Together these data highlight the ability of this biomechanically active platform to model VILI and its associated components and how such systems can be used as a predictive tool for determining regions that are predisposed to injury when subjected to mechanical ventilation.

\section{Device Supports Human Alveolar Cell Cultures}

Finally, we examined the potential of the platform to support human primary alveolar epithelial type 2 (hAT2) cells and human iPSCderived alveolar type 2 (iAT2) cells. These cells were grown as alveolospheres in 3D cultures before dissociating them and seeding them onto the devices. Although the device can support long-term cultures of the cells (Supplementary Figure S7), hAT2 cells readily differentiate into alveolar type 1 (AT1) cells in 2D cultures and cease surfactant production. Therefore, the studies reported here were performed within $48 \mathrm{~h}$ of seeding the cells. The primary hAT2 cells were seeded at a density of 60,000 cells/ $\mathrm{cm}^{2}$ and cultured on collagen type 1-coated membranes. The cells were exposed to breathing-like motion for $24 \mathrm{~h}$ and compared against the corresponding static cultures. We observed significantly higher levels of pro SP-C in cells that encountered breathing-like motions (Figures 6A, B). Additionally, we also observed distinct differences in cell morphology between the two conditions, wherein the cells that were exposed to breathing-like motions were significantly more rounded than cells in static conditions (Figure 6C). The 
roundness of the cell, which is defined as $\frac{4 * a r e a}{\pi * m a j o r a x i s^{2}}$, was uniform across the device cultured in the static condition and no difference was observed between the center and edge of the membrane. On the contrary, the cells that were exposed to breathing-like motions displayed a significant difference between the edge and the center of the membrane. The cells at the center of the membrane were significantly more rounded than those at the edges, likely due to the spatially heterogeneous strain profile in the two regions (Supplementary Figure S8). We observed similar results with iAT2 cells, where cells cultured under breathing-like movements displayed significantly higher expression of proSPC as than static cultures (Figures 6D, E). As observed with primary hAT2 cells, iAT2 displayed more rounded morphologies in breathing-like conditions as than cells in static conditions (Figure 6F), although spatial differences in morphology were not observed in these cells. These results highlight the ability of culturing human alveolar epithelial cells within the device, a more clinically relevant cell source to model tissue-specific functions.

\section{CONCLUSION}

This study describes the development of a microfluidic-pneumatic platform consisting of pneumatic and fluidic chambers separated by a thin membrane that supports alveolar epithelial cell culture. The device utilizes out-of-plane stretching of the membrane via cyclic air pressurization to mimic strain heterogeneity experienced during alveolar expansion due to breathing, thus allowing us to study the effect of strain heterogeneity within a single device.

Our results show that breathing-like motions and micromechanics in the local environment had a significant effect on cell morphology and critical functions of alveolar epithelial cells, such as surfactant production. We also utilized this platform to model VILI by incorporating transpulmonary pressure. One of the limitations of the current study is that the dimensions of the membrane used are much greater than alveolar size, which can prevent the cells from feeling curvature at a cellular level during stretch (Nossa et al., 2021). The length scale of the alveolar architecture will have a significant effect on the strain heterogeneity generated from breathing-like motions. Recent studies have recapitulated alveolar size and curvature within lungon-chip systems (Huang et al., 2021; Zamprogno et al., 2021), although further studies are needed to characterize heterogeneous strain and its effect on cells within such systems mimicking the alveolar architecture. While our device incorporates only the epithelial cells in its current configuration, our approach provides a framework for developing more complex systems that capture alveolar micromechanics and spatial strain heterogeneity. The incorporation of other distal lung cells such as fibroblasts within these devices will facilitate the study of progressive changes in lung biomechanics in diseases involving heterotypic cell-cell interactions such as pulmonary fibrosis. Replacing the non-porous PDMS membrane used in this study with porous membranes would allow cell-cell interactions, while also enabling air-liquid interface culture (Huh et al., 2010; Stucki et al., 2018; Doryab et al., 2021a, Doryab et al., 2021b; Huang et al., 2021; Zamprogno et al., 2021). Finally, although we have only modeled positive pleural pressure by raising the height of the syringe, negative pleural pressure can be similarly modeled by lowering the syringe height below the device height and dynamic pleural pressure changes by using an automated system that adjusts the height of the syringe in concert with the air pressure. Apart from providing insights into the role of biomechanics on lung function, these platforms can also potentially serve as important predictive tools to prevent lung injuries or for drug screening (Artzy-Schnirman et al., 2021).

\section{DATA AVAILABILITY STATEMENT}

The raw data supporting the conclusions of this article will be made available by the authors, without undue reservation.

\section{AUTHOR CONTRIBUTIONS}

SV and VK conceived the idea. VK, SP, and AG performed the experiments and collected the data. JH helped with the synthesis of chemicals. AT helped with human lung cell isolation. All authors wrote and edited the manuscript.

\section{FUNDING}

The authors would like to acknowledge support from the Kaganov Research Initiative grant from Duke. The authors would also like to acknowledge support from NIH grant 3UH3TR002142-04S1. Part of this study was performed at the Duke University Shared Materials Instrumentation Facility (SMIF), a member of the North Carolina Research Triangle Nanotechnology Network (RTNN), which is supported by the National Science Foundation (award number ECCS-2025064) as part of the National Nanotechnology Coordinated Infrastructure (NNCI).

\section{ACKNOWLEDGMENTS}

We acknowledge the BioRepository and Precision Pathology Center (BRPC), a shared resource of the Duke University School of Medicine and Duke Cancer Institute, for supporting this project under Institutional Review Board oversight. The infrastructure receives support from P30 CA014236 and UM1 CA239755. We would also like to thank Dr. Darrell N. Kotton at Boston University and his laboratory members for providing the iAT2 cells.

\section{SUPPLEMENTARY MATERIAL}

The Supplementary Material for this article can be found online at: https://www.frontiersin.org/articles/10.3389/fbioe.2022.848699/ full\#supplementary-material 


\section{REFERENCES}

Agrawal, G., Aung, A., and Varghese, S. (2017). Skeletal Muscle-On-A-Chip: an In Vitro Model to Evaluate Tissue Formation and Injury. Lab. Chip 17, 3447-3461. doi:10.1039/C7LC00512A

Artzy-Schnirman, A., Arber Raviv, S., Doppelt Flikshtain, O., Shklover, J., Korin, N., Gross, A., et al. (2021). Advanced Human-Relevant In Vitro Pulmonary Platforms for Respiratory Therapeutics. Adv. Drug Deliv. Rev. 176, 113901. doi:10.1016/j.addr.2021.113901

Aung, A., Bhullar, I. S., Theprungsirikul, J., Davey, S. K., Lim, H. L., Chiu, Y.-J., et al. (2016). 3D Cardiac $\mu$ tissues within a Microfluidic Device with Real-Time Contractile Stress Readout. Lab. Chip 16, 153-162. doi:10.1039/C5LC00820D

Aung, A., Kumar, V., Theprungsirikul, J., Davey, S. K., and Varghese, S. (2020). An Engineered Tumor-On-A-Chip Device with Breast Cancer-Immune Cell Interactions for Assessing T-Cell Recruitment. Cancer Res. 80, 263-275. doi:10.1158/0008-5472.CAN-19-0342

Beitler, J. R., Malhotra, A., and Thompson, B. T. (2016). Ventilator-induced Lung Injury. Clin. Chest Med. 37, 633-646. doi:10.1016/j.ccm.2016.07.004

Benam, K. H., Mazur, M., Choe, Y., Ferrante, T. C., Novak, R., and Ingber, D. E. (2017). Human Lung Small Airway-On-A-Chip Protocol. Methods Mol. Biol. 1612, 345-365. doi:10.1007/978-1-4939-7021-6_25

Benam, K. H., Novak, R., Nawroth, J., Hirano-Kobayashi, M., Ferrante, T. C., Choe, Y., et al. (2016a). Matched-Comparative Modeling of Normal and Diseased Human Airway Responses Using a Microengineered Breathing Lung Chip. Cel Syst. 3, 456-466. e4. doi:10.1016/j.cels.2016.10.003

Benam, K. H., Villenave, R., Lucchesi, C., Varone, A., Hubeau, C., Lee, H.-H., et al. (2016b). Small Airway-On-A-Chip Enables Analysis of Human Lung Inflammation and Drug Responses In Vitro. Nat. Methods 13, 151-157. doi:10.1038/nmeth.3697

Bhatia, S. N., and Ingber, D. E. (2014). Microfluidic Organs-On-Chips. Nat. Biotechnol. 32, 760-772. doi:10.1038/nbt.2989

Birukov, K. G., Jacobson, J. R., Flores, A. A., Ye, S. Q., Birukova, A. A., Verin, A. D., et al. (2003). Magnitude-dependent Regulation of Pulmonary Endothelial Cell Barrier Function by Cyclic Stretch. Am. J. Physiology-Lung Cell Mol. Physiol. 285, L785-L797. doi:10.1152/ajplung.00336.2002

Chen, Z.-1., Chen, Y.-z., and Hu, Z.-y. (2014). A Micromechanical Model for Estimating Alveolar wall Strain in Mechanically Ventilated Edematous Lungs. J. Appl. Physiol. 117, 586-592. doi:10.1152/japplphysiol.00072.2014

Doryab, A., Taskin, M. B., Stahlhut, P., Schröppel, A., Orak, S., Voss, C., et al. (2021a). A Bioinspired In Vitro Lung Model to Study Particokinetics of Nano-/ Microparticles under Cyclic Stretch and Air-Liquid Interface Conditions. Front. Bioeng. Biotechnol. 9, 616830. doi:10.3389/fbioe.2021.616830

Doryab, A., Taskin, M. B., Stahlhut, P., Schröppel, A., Wagner, D. E., Groll, J., et al. (2021b). A Biomimetic, Copolymeric Membrane for Cell-Stretch Experiments with Pulmonary Epithelial Cells at the Air-Liquid Interface. Adv. Funct. Mater. 31, 2004707. doi:10.1002/adfm.202004707

Elias-Kirma, S., Artzy-Schnirman, A., Das, P., Heller-Algazi, M., Korin, N., and Sznitman, J. (2020). In Situ-Like Aerosol Inhalation Exposure for Cytotoxicity Assessment Using Airway-On-Chips Platforms. Front. Bioeng. Biotechnol. 8, 91. doi:10.3389/fbioe.2020.00091

Faffe, D. S., and Zin, W. A. (2009). Lung Parenchymal Mechanics in Health and Disease. Physiol. Rev. 89, 759-775. doi:10.1152/physrev.00019.2007

Felder, M., Trueeb, B., Stucki, A. O., Borcard, S., Stucki, J. D., Schnyder, B., et al. (2019). Impaired Wound Healing of Alveolar Lung Epithelial Cells in a Breathing Lung-On-A-Chip. Front. Bioeng. Biotechnol. 7, 3. doi:10.3389/ fbioe.2019.00003

Guenat, O. T., and Berthiaume, F. (2018). Incorporating Mechanical Strain in Organs-On-A-Chip: Lung and Skin. Biomicrofluidics 12, 042207. doi:10.1063/1. 5024895

Harris, R. S. (2005). Pressure-volume Curves of the Respiratory System. Respir. Care 50 (1), 78-79.

Hsia, C. C. W., Hyde, D. M., and Weibel, E. R. (2016). Lung Structure and the Intrinsic Challenges of Gas Exchange. Compr. Physiol. 6, 827-895. doi:10.1002/ cphy.c150028

Huang, D., Liu, T., Liao, J., Maharjan, S., Xie, X., Pérez, M., et al. (2021). Reversedengineered Human Alveolar Lung-On-A-Chip Model. Proc. Natl. Acad. Sci. USA 118, e2016146118. doi:10.1073/pnas.2016146118
Huh, D., Leslie, D. C., Matthews, B. D., Fraser, J. P., Jurek, S., Hamilton, G. A., et al (2012). A Human Disease Model of Drug Toxicity-Induced Pulmonary Edema in a Lung-On-A-Chip Microdevice. Sci. Transl. Med. 4, 159ra147 LP. doi:10. 1126/scitranslmed.3004249

Huh, D., Matthews, B. D., Mammoto, A., Montoya-Zavala, M., Hsin, H. Y., and Ingber, D. E. (2010). Reconstituting Organ-Level Lung Functions on a Chip. Science 328, 1662 LP-1668. doi:10.1126/science.1188302

Hurtado, D. E., Erranz, B., Lillo, F., Sarabia-Vallejos, M., Iturrieta, P., Morales, F., et al. (2020). Progression of Regional Lung Strain and Heterogeneity in Lung Injury: Assessing the Evolution under Spontaneous Breathing and Mechanical Ventilation. Ann. Intensive Care 10, 107. doi:10.1186/s13613020-00725-0

Ingenito, E. P., Tsai, L. W., Majumdar, A., and Suki, B. (2005). On the Role of Surface Tension in the Pathophysiology of Emphysema. Am. J. Respir. Crit. Care Med. 171, 300-304. doi:10.1164/rccm.200406-770PP

Ishahak, M., Hill, J., Amin, Q., Wubker, L., Hernandez, A., Mitrofanova, A., et al. (2020). Modular Microphysiological System for Modeling of Biologic Barrier Function. Front. Bioeng. Biotechnol. 8, 581163. doi:10.3389/fbioe.2020.581163

Jacob, A., Vedaie, M., Roberts, D. A., Thomas, D. C., Villacorta-Martin, C., Alysandratos, K.-D., et al. (2019). Derivation of Self-Renewing Lung Alveolar Epithelial Type II Cells from Human Pluripotent Stem Cells. Nat. Protoc. 14, 3303-3332. doi:10.1038/s41596-019-0220-0

Jain, A., Barrile, R., van der Meer, A., Mammoto, A., Mammoto, T., De Ceunynck, K., et al. (2018). Primary Human Lung Alveolus-On-A-Chip Model of Intravascular Thrombosis for Assessment of Therapeutics. Clin. Pharmacol. Ther. 103, 332-340. doi:10.1002/cpt.742

Jimenez-Valdes, R. J., Can, U. I., Niemeyer, B. F., and Benam, K. H. (2020). Where We Stand: Lung Organotypic Living Systems that Emulate Human-Relevant Host-Environment/Pathogen Interactions. Front. Bioeng. Biotechnol. 8, 989. doi:10.3389/fbioe.2020.00989

Katsura, H., Sontake, V., Tata, A., Kobayashi, Y., Edwards, C. E., Heaton, B. E., et al. (2020). Human Lung Stem Cell-Based Alveolospheres Provide Insights into SARS-CoV-2-Mediated Interferon Responses and Pneumocyte Dysfunction. Cell Stem Cell 27, 890-904. e8. doi:10.1016/j.stem.2020.10.005

Khalid, M. A. U., Kim, Y. S., Ali, M., Lee, B. G., Cho, Y.-J., and Choi, K. H. (2020). A Lung Cancer-On-Chip Platform with Integrated Biosensors for Physiological Monitoring and Toxicity Assessment. Biochem. Eng. J. 155, 107469. doi:10. 1016/j.bej.2019.107469

Knudsen, L., and Ochs, M. (2018). The Micromechanics of Lung Alveoli: Structure and Function of Surfactant and Tissue Components. Histochem. Cel Biol. 150, 661-676. doi:10.1007/s00418-018-1747-9

Kumar, V., and Varghese, S. (2019). Ex Vivo Tumor-on-a-Chip Platforms to Study Intercellular Interactions within the Tumor Microenvironment. Adv. Healthc. Mater. 8, 1801198. doi:10.1002/adhm.201801198

Low, L. A., Mummery, C., Berridge, B. R., Austin, C. P., and Tagle, D. A. (2021). Organs-on-chips: into the Next Decade. Nat. Rev. Drug Discov. 20, 345-361. doi:10.1038/s41573-020-0079-3

Martinez, F., Lewis, J., Copland, I., Engelberts, D., Kavanagh, B. P., Post, M., et al. (2004). Mechanical Ventilation Effect on Surfactant Content, Function, and Lung Compliance in the Newborn Rat. Pediatr. Res. 56, 19-25. doi:10.1203/01. PDR.0000128980.82797.29

Mejías, J. C., Nelson, M. R., Liseth, O., and Roy, K. (2020). A 96-well Format Microvascularized Human Lung-On-A-Chip Platform for Microphysiological Modeling of Fibrotic Diseases. Lab. Chip 20, 3601-3611. doi:10.1039/ D0LC00644K

Nawroth, J. C., Lucchesi, C., Cheng, D., Shukla, A., Ngyuen, J., Shroff, T., et al. (2020). A Microengineered Airway Lung Chip Models Key Features of ViralInduced Exacerbation of Asthma. Am. J. Respir. Cel Mol. Biol. 63, 591-600. doi:10.1165/rcmb.2020-0010MA

Neidlinger-Wilke, C., Grood, E., Claes, L., and Brand, R. (2002). Fibroblast Orientation to Stretch Begins within Three Hours. J. Orthop. Res. 20, 953-956. doi:10.1016/S0736-0266(02)00024-4

Nossa, R., Costa, J., Cacopardo, L., and Ahluwalia, A. (2021). Breathing In Vitro: Designs and Applications of Engineered Lung Models. J. Tissue Eng. 12, 204173142110086. doi:10.1177/20417314211008696

Park, J. Y., Ryu, H., Lee, B., Ha, D.-H., Ahn, M., Kim, S., et al. (2018). Development of a Functional Airway-On-A-Chip by 3D Cell Printing. Biofabrication 11, 015002. doi:10.1088/1758-5090/aae545 
Perlman, C. E., Lederer, D. J., and Bhattacharya, J. (2011). Micromechanics of Alveolar Edema. Am. J. Respir. Cel Mol. Biol. 44, 34-39. doi:10.1165/rcmb.2009$0005 \mathrm{OC}$

Plantier, L., Cazes, A., Dinh-Xuan, A.-T., Bancal, C., Marchand-Adam, S., and Crestani, B. (2018). Physiology of the Lung in Idiopathic Pulmonary Fibrosis. Eur. Respir. Rev. 27, 170062. doi:10.1183/16000617.0062-2017

Püspöki, Z., Storath, M., Sage, D., and Unser, M. (2016). Transforms and Operators for Directional Bioimage Analysis: A Survey. Adv. Anat. Embryol. Cel Biol. 219, 69-93. doi:10.1007/978-3-319-28549-8_3

Rivlin, R. S. (1948). Large Elastic Deformations of Isotropic Materials IV. Further Developments of the General Theory. Phil. Trans. R. Soc. Lond. A. 241, 379-397. doi:10.1098/rsta.1948.0024

Roan, E., and Waters, C. M. (2011). What Do We Know about Mechanical Strain in Lung Alveoli? Am. J. Physiology-Lung Cell Mol. Physiol. 301, L625-L635. doi:10. 1152/ajplung.00105.2011

Sanchez-Esteban, J., Tsai, S.-W., Sang, J., Qin, J., Torday, J. S., and Rubin, L. P. (1998). Effects of Mechanical Forces on Lung-specific Gene Expression. Am. J. Med. Sci. 316, 200-204. doi:10.1097/00000441-199809000-00009

Shrestha, J., Razavi Bazaz, S., Aboulkheyr Es, H., Yaghobian Azari, D., Thierry, B., Ebrahimi Warkiani, M., et al. (2020). Lung-on-a-chip: the Future of Respiratory Disease Models and Pharmacological Studies. Crit. Rev. Biotechnol. 40, 213-230. doi:10.1080/07388551.2019.1710458

Shrestha, J., Ryan, S. T., Mills, O., Zhand, S., Razavi Bazaz, S., Hansbro, P. M., et al. (2021). A 3D-Printed Microfluidic Platform for Simulating the Effects of CPAP on the Nasal Epithelium. Biofabrication 13, 035028. doi:10.1088/1758-5090/ abe4c1

Smith, B. J. (2016). Strain Heterogeneity in the Injured Lung: Cause or Consequence? J. Appl. Physiol. 121, 1363-1364. doi:10.1152/japplphysiol. 00818.2016

Stucki, A. O., Stucki, J. D., Hall, S. R. R., Felder, M., Mermoud, Y., Schmid, R. A., et al. (2015). A Lung-On-A-Chip Array with an Integrated Bio-Inspired Respiration Mechanism. Lab. Chip 15, 1302-1310. doi:10.1039/C4LC01252F

Stucki, J. D., Hobi, N., Galimov, A., Stucki, A. O., Schneider-Daum, N., Lehr, C.-M., et al. (2018). Medium Throughput Breathing Human Primary Cell AlveolusOn-Chip Model. Sci. Rep. 8, 14359. doi:10.1038/s41598-018-32523-x

Sznitman, J. (2021). Revisiting Airflow and Aerosol Transport Phenomena in the Deep Lungs with Microfluidics. Chem. Rev. doi:10.1021/acs.chemrev.1c00621
Torday, J. S., and Rehan, V. K. (2002). Stretch-stimulated Surfactant Synthesis Is Coordinated by the Paracrine Actions of PTHrP and Leptin. Am. J. Physiology-Lung Cell Mol. Physiol. 283, L130-L135. doi:10.1152/ajplung. 00380.2001

Winkler, M., Simon, M. G., Vu, T., Gartner, T. L., Jester, J. V., Lee, A. P., et al. (2014). A Microfabricated, Optically Accessible Device to Study the Effects of Mechanical Cues on Collagen Fiber Organization. Biomed. Microdevices 16, 255-267. doi:10.1007/s10544-013-9829-X

Yoon, S.-H., Reyes-Ortiz, V., Kim, K.-H., Seo, Y. H., and Mofrad, M. R. K. (2010). Analysis of Circular PDMS Microballoons with Ultralarge Deflection for MEMS Design. J. Microelectromech. Syst. 19, 854-864. doi:10.1109/JMEMS. 2010.2049984

Zacharias, W. J., Frank, D. B., Zepp, J. A., Morley, M. P., Alkhaleel, F. A., Kong, J., et al. (2018). Regeneration of the Lung Alveolus by an Evolutionarily Conserved Epithelial Progenitor. Nature 555, 251-255. doi:10.1038/nature25786

Zamprogno, P., Wüthrich, S., Achenbach, S., Thoma, G., Stucki, J. D., Hobi, N., et al. (2021). Second-generation Lung-On-A-Chip with an Array of Stretchable Alveoli Made with a Biological Membrane. Commun. Biol. 4, 168. doi:10.1038/ s42003-021-01695-0

Conflict of Interest: The authors declare that the research was conducted in the absence of any commercial or financial relationships that could be construed as a potential conflict of interest.

Publisher's Note: All claims expressed in this article are solely those of the authors and do not necessarily represent those of their affiliated organizations, or those of the publisher, the editors, and the reviewers. Any product that may be evaluated in this article, or claim that may be made by its manufacturer, is not guaranteed or endorsed by the publisher.

Copyright (c) 2022 Kumar, Madhurakkat Perikamana, Tata, Hoque, Gilpin, Tata and Varghese. This is an open-access article distributed under the terms of the Creative Commons Attribution License (CC BY). The use, distribution or reproduction in other forums is permitted, provided the original author(s) and the copyright owner(s) are credited and that the original publication in this journal is cited, in accordance with accepted academic practice. No use, distribution or reproduction is permitted which does not comply with these terms. 